\title{
Genetic variation of Fraxinus excelsior half-sib families in response to ash dieback disease following simulated spring frost and summer drought treatments
}

\author{
Alfas Pliura ${ }^{(1-2)}$, \\ Vaidotas Lygis ${ }^{(3)}$, \\ Diana Marčiulyniene ${ }^{(1)}$, \\ Vytautas Suchockas ${ }^{(1-2)}$, \\ Remigijus Bakys ${ }^{(1)}$
}

\begin{abstract}
Ten juvenile Fraxinus excelsior half-sib families from two Lithuanian populations have been tested in the controlled environment for their response to ash dieback disease caused by Hymenoscyphus fraxineus, detecting changes of genetic variation and heritability, as well as estimating genotype by environment $(G \times E)$ interaction and phenotypic plasticity following artificial spring frost and summer drought treatments. In 2014, a batch of 200 four-year-old ash seedlings was used for each treatment and control (no treatment). Health condition, bud flushing phenology and height were assessed for each seedling, and disease incidence and survival ratios were assessed for each family both before (at the beginning of the vegetation season) and after the treatments (at the end of the vegetation season). Disease incidence ratio increased from $0.77-0.80$ up to $0.90-0.95$. Tree mortality rates during one vegetation season were significantly lower in the frost treatment (21\%) than in the drought treatment $(25 \%)$ or control $(31 \%)$. None of the tested $F$. excelsior families were completely resistant to ash dieback, although significant among-family differences in disease incidence and damage rates suggest an additive mode of gene action and thus a quantitative resistance to the disease. Neither disease incidence rates, nor tree health condition scores differed significantly among the applied treatments (including control) indicating in general a negligible effect of the simulated adverse conditions on health status of the ash seedlings. However, $G \times E$ interaction was found to be significant (at $P>0.05$ ) for disease incidence, length of necrotic shoots and tree survival, implying that sus ceptibility of ash families to the dieback disease unequally depends on environmental conditions, and indicating a presence of genetic variation in plasticity and reaction norms of the tested families across environments (treatments). Substantially increased coefficients of additive genetic variation and heritability in health condition following both frost and drought treatments and compared to control showed that simulated stress conditions may noticeably contribute to expression of differences among the tested $F$. excelsior families in their resistance traits, thus enabling a better evaluation of performance of different families, an effective family selection for resistance, and achievement of a marked genetic gain.
\end{abstract}

Keywords: Common Ash, Dieback, Disease Resistance, Genetic Variation, Heritability, Hymenoscyphus pseudoalbidus (Chalara fraxinea), Phenotypic Plasticity

\section{Introduction}

Since 1992, a severe dieback of common ash (Fraxinus excelsior L.) has spread from Eastern Poland to many European coun- tries (Gross et al. 2014 and references therein). The disease is caused by the ascomycete fungus Hymenoscyphus fraxineus (T. Kowalski) Baral et al. (=Chalara fraxinea
(1) Institute of Forestry, Lithuanian Research Centre for Agriculture and Forestry, Liepu str. 1, LT-53101 Girionys, Kaunas reg. (Lithuania); (2) Aleksandras Stulginskis University, Studentu str. 13, LT-53361 Akademija - Kaunas (Lithuania); (3) Institute of Botany of Nature Research Centre, Zaliuju Ežeru str. 49, LT-08406 Vilnius (Lithuania)

@ Alfas Pliura (genetsk@mi.lt)

Received: Nov 26, 2014 - Accepted: Jul 24, 2015

Citation: Pliura A, Lygis V, Marčiulyniene D, Suchockas V, Bakys R (2015). Genetic variation of Fraxinus excelsior half-sib families in response to ash dieback disease following simulated spring frost and summer drought treatments. iForest 9: 12-22. - doi: 10.3832/ifor1514-008 [online 2015-09-08]

Communicated by: Alberto Santini
T. Kowalski, syn. Hymenoscyphus pseudoalbidus - Queloz et al. 2010), which in Europe is an invasive species (Husson et al. 2011, Gross et al. 2014). The disease causes wilting and necroses of ash leaves and petioles, necrotic lesions on stems, branches and shoots, stem cankers and wood discolouration, followed by a gradual crown dieback, and in most severe cases - death of an entire tree (Bakys et al. 2009, Kowalski \& Holdenrieder 2009a, 2009b, Kirisits et al. 2009, Skovsgaard et al. 2010). In Lithuania, dieback of $F$. excelsior was first observed in 1995-1996 in the north-central part of the country (Juodvalkis \& Vasiliauskas 2002) and since then large areas of ash stands underwent sanitary fellings (Lygis et al. 2014). Currently, the disease is in its chronic phase, and the health condition of the remaining ash stands continues to deteriorate; yet, no effective control measures have been offered so far (Gustiene 
2010, Pliura et al. 2011, Lygis et al. 2014). Consequently, the density of ash trees in a stand is often reduced to few individuals per hectare, meaning that the effective population size $\left(N_{e}\right)$ has also decreased, thus compromising the genetic diversity of F. excelsior in mature stands and in regenerating offspring (Pliura et al. 2011).

Studies in natural stands, clonal seed orchards and progeny trials in a number of European countries provide evidence of existing substantial genetic variation at individual, clonal, family and population levels in the susceptibility of $F$. excelsior to $H$. fraxineus, and that there is a significant genetic heritability in disease resistance/tolerance (Pliura \& Baliuckas 2007, McKinney et al. 2011, Pliura et al. 2011, Kirisits \& Freinschlag 2012, Kjær et al. 2012, Stener 2013, Pliura et al. 2014, Enderle et al. 2015). The genetically inherited resistance may provide a basis for a natural adaptation. The success of breeding programs is also determined to a great extent by the presence of sufficient genetic variation in a breeding population, as well as by sufficient heritability of resistance traits that facilitate identification and selection of truly resistant genotypes. Progeny studies show that disease incidence and severity varies among test sites, which was in general explained by the influence of different infection loads and/or environment conditions (Pliura \& Baliuckas 2007, McKinney et al. 2011, Pliura et al. 2011, 2014, Kirisits \& Freinschlag 2012, Kjær et al. 2012, Stener 2013). It remains unknown to what extent changes in environmental conditions (e.g., from normal to stressed) can influence the disease development and spread among trees, and how this contributes to changes in genetic parameters such as coefficient of genetic variation, heritability and genetic correlations among the tree traits.

Two strategies of plant adaptation can be distinguished: (i) adaptation via genetic variation, and (ii) adaptation via phenotypic plasticity (Schmalhausen 1949). Following environmental changes, a population that has a considerable genetic variation adapts through survival and reproduction of the most resistant genotypes, while maladapted genotypes disappear due to natural selection. When rapid adaptation is required, or when genetic variation is lacking, plants respond to changes in the environment by modifying their phenotype (Schmalhausen 1949). This specific response to a certain range of conditions for a single or a set of traits is called phenotypic plasticity (Bradshaw 1965). Studies of plastic response along an environmental gradient indicate that reaction norms vary significantly among genotypes (Gregorius \& Namkoong 1986, Namkoong et al. 1992). There are continuous debates over whether phenotypic plasticity shields genotypes from selection or generates novel opportunities for selection to act (Ghalambor et al. 2007). One hypothesis suggests that genetic variation and plasticity represent alter- native strategies for coping with environment heterogeneity (Marshall \& Jain 1968, Jain 1979). Other hypotheses however suggest that genetic variation and phenotypic plasticity are positively correlated (Gillespie \& Turelli 1989, Goldstein \& Holsinger 1992). The phenotypic plasticity can be considered to be a trait in itself that is under genetic control, and which can evolve independently of the trait (Bradshaw 1965, Schlichting \& Levin 1984, Schlichting 1986, Scheiner 1993a, Scheiner 1993b). Phenotypic plasticity encompasses diverse adaptive and non-adaptive responses to the environment variation (Ghalambor et al. 2007).

A phenotypic response can be adaptive when it enhances plant fitness in a changed environment (Sultan \& Bazzaz 1993), or non-adaptive when it results in deterioration of fitness/condition of an individual plant which reflects an inevitable metabolic or developmental response (Sultan 1987, Sultan 1995). Good adaptation to heterogeneous environments can be achieved by phenotypic plasticity or by stability (canalization). In the first case, populations may be subjected to a selection resulting in specialized genotypes of high plasticity that perform better in an indigenous (optimal) environment than in an unaccustomed environment (Taylor \& Aarssen 1988). The second case refers to a situation when selection favors genotypes capable of buffering their phenotypes in the changed environment. Thus, the phenotypic plasticity of such genotypes is low. It has been concluded that the adaptive plasticity that places populations close enough to a new phenotypic optimum for directional selection to act is the only plasticity that predictably enhances fitness and is most likely to facilitate adaptive evolution (Ghalambor et al. 2007). On the other hand, the authors pointed up that in stressful environments, the non-adaptive plasticity can result in a response being further away from the optimum or increase the variance due to the expression of cryptic genetic variation. The role of the phenotypic plasticity in plant susceptibility (degree of damage) to diseases/genetic resistance in expression of cryptic genetic variation, natural selection and adaptation processes remains unclear and definitely deserves further studies. Plasticity and plasticity-related changes in genetic variation and heritability in the incidence of the ash dieback disease under spring frosts and summer drought have never been assessed. Searching for not only resistant ash genotypes, but also for heritable adaptability traits and environment conditions under which its largest genetic variation and highest heritability can be obtained may be one of the most promising strategies in breeding for resistance to restore damaged $F$. excelsior stands.

The main aim of the present study was to assess the susceptibility of ten juvenile $F$. excelsior half-sib families to ash dieback disease caused by $H$. fraxineus, and to detect changes in genetic variation and heritability of disease resistance traits as well as to estimate genotype by environment $(G \times E)$ interaction and phenogenetic plasticity of selected ash families following simulated spring frost and summer drought treatments.

\section{Materials and methods}

\section{Material}

Ten half-sib families of $F$. excelsior originating from two northern Lithuanian populations heavily damaged by $H$. fraxineus (and therefore having undergone strong natural selection) were selected for the present experiment: Biržai (families no. B080, B076, B069, B078, B072 - 56 ${ }^{\circ} 15^{\prime} 25^{\prime \prime}$ $\mathrm{N}, 24^{\circ} 34^{\prime} 30^{\prime \prime} \mathrm{E}$ ) and Zeimelis (families no. Z049, Z053, Zo54, Zo6o, Zo61 - 56 '15' 45' $\left.\mathrm{N}, 24^{\circ} 02^{\prime} 32^{\prime \prime} \mathrm{E}\right)$. Seeds from the respective families were collected in autumn 2008, stratified and sown in spring 2010 in a forest nursery at Dubrava Experimental-Educational State Forest Enterprise (EESFE) located in Kaunas region, central Lithuania. The seedlings were grown outdoors at the same forest nursery for two years. In spring 2012, 60 two-year-old seedlings of generally good health condition (very few with external disease symptoms) were selected from each family (in total 600 seedlings), planted in 5 -liter plastic pots containing peat substrate and grown for another two years (until May 2014) under standard greenhouse conditions. In the greenhouse, the pots were arranged with $0.2 \times 0.2 \mathrm{~m}$ spacing, and regular watering and fertilization was applied.

\section{Treatments}

In early May 2014, ash juveniles to be used for spring frost, summer drought and control treatments were randomly selected among the 600 four-year-old potted trees, according to the available number of trees in groups of different health conditions (scored from 1 - tree with dry stem and branches - to 5 - externally healthy tree, modified from Pliura et al. 2011) within each family. The following approach was used to randomly distribute trees among the treatments: prior to the treatments, in each family, the pots with ash seedlings were grouped into five batches representing different health condition classes, then plants from each of those five batches were randomly selected to form three batches (each consisting of four plants) to be used in different treatments. As a result, a batch of 200 trees (10 families, 20 trees per family) was formed for each treatment. The trials (treatments) were established in a randomized complete block design with 2 blocks, each consisting of ten trees per family.

On May 16, 2014, a batch of 200 trees assigned for the simulated spring frost treatment was placed in a PE2422UVLX climatic chamber (Angelantoni Test Technologies, Massa Martana, Italy). The tempera- 
ture in the climatic chamber was first gradually (in one hour) reduced from $+20^{\circ} \mathrm{C}$ to $-5{ }^{\circ} \mathrm{C}$, then held at $-5{ }^{\circ} \mathrm{C}$ for 30 minutes, and finally was gradually (in one hour) raised back to $+20{ }^{\circ} \mathrm{C}$. After this cycle, trees were taken out of the climatic chamber and further grown outdoors for one vegetation season in the forest nursery of Dubrava EESFE. Watering was applied when needed depending on weather conditions. During the applied spring frost treatment, leaves of the ash seedlings became black and wilted. New leaves flushed and shoots resprouted from adventitious latent buds on almost all terminal and lateral shoots in two weeks (by the end of May 2014).

Concurrently, batches of seedlings assigned to the control and summer drought treatments were moved from the greenhouse to the outdoor nursery and placed next to the spring frost-treated seedlings. Watering was applied equally to all seedlings when needed, depending on weather conditions. On June 20, 2014, a batch of 200 trees assigned for the summer drought treatment was transported to the greenhouse, and left there for two weeks without any watering until severe wilting of leaves occurred. During this treatment, the temperature in the greenhouse varied from +25 to $+35^{\circ} \mathrm{C}$ during day time, and relative air humidity varied between $40-60 \%$. Thereafter, trees were transported back to the outdoor nursery and watered regularly (depending on weather conditions). Leaves regained turgor and shoots regained growth as soon as the watering was applied.

\section{Assessment of tree biometric} parameters and sanitary conditions

Measurement of tree biometric parameters and scoring of the extent of damage by $\mathrm{H}$. fraxineus were performed in May 2012 (during outplanting of the ash seedlings into plastic pots), and repeated in August 2013, on May 5, 2014 (before the treatments), and on September 3, 2014 (at the end of vegetation season, after the treatments). The assessed traits were: (1) disease incidence ratio (the ratio between the number of symptomatic trees and the total number of trees in a family); (2) health condition of an individual tree (scored between 1 - tree with dry stem and branches - and 5 - externally healthy tree -, Pliura et al. 2011); (3) survival ratio (the ratio between the number of living and dead trees in a family); (4) seedling height; (5) total length of necroses on leader and lateral shoots in an individual plant; and (6) total length of necrotic lesions formed on leader and lateral shoots and stem of an individual plant. Bud flushing phenology was assessed in beginning of May 2014 when all phases were present and distribution of scores was closest to normal, using a categorical scale of five degrees (points) adopted from Douglas et al. (2013): 5 - very early; 4 - early; 3 - of moderate earliness; 2 - late; and 1 - very late flushing.

\section{Variance analysis}

The variance analysis of the data was done using the MIXED procedure of the SAS software package (SAS ${ }^{\circledast}$ Analytics Pro 12.1 - SAS Institute Inc 2012), which uses Mixed model equations (MME) and the restricted maximum likelihood (REML) method. The significance of fixed effects (of block and treatment) was tested with F-tests. The significance of the random effects was tested using Z-test $\left(\mathrm{SAS}^{\circledast}\right.$ Analytics Pro 12.1 - SAS Institute Inc 2012). The analysis was performed separately for spring frost and summer drought treatments, and in both cases included the same control batch of trees. The combined linear statistic model was used for joint analysis of data from treatments' and control batches together (eqn. 1):

$$
y_{i j k l m}=\mu+z_{i}+b_{j}+p_{k}+f_{l}+f_{l} z_{i}+\varepsilon_{i j k l m}
$$

where $y_{\mathrm{ijk} / \mathrm{m}}$ is an observation of the $m^{\text {th }}$ tree from the $l^{\text {th }}$ family in the $k^{\text {th }}$ population in the $j^{\text {th }}$ block of the $i^{\text {th }}$ environment (treatment), $\mu$ is the overall mean, $z_{\mathrm{i}}$ is the fixed effect of the $i^{\text {th }}$ environment, $b_{\mathrm{j}}$ is the $j^{\text {th }}$ block effect, $p_{\mathrm{k}}$ is the $k^{\text {th }}$ population effect, $f_{1}$ is the effect of $l^{\text {th }}$ family, $f_{1} \cdot z_{\mathrm{i}}$ is the interaction effect of $l^{\text {th }}$ family and $i^{\text {th }}$ environment (treatment), $\varepsilon_{i \mathrm{ik} \mid m}$ is the random residual. The population effect later was omitted from the model as in most cases it was non-significant. The model assumed that random effects were normally distributed with expectation zero and corresponding variances: $\sigma_{\mathrm{p}}{ }^{2}, \sigma_{\mathrm{f}}{ }^{2}, \sigma_{\mathrm{f} \cdot \mathrm{z}}{ }^{2}$ and $\sigma_{\mathrm{e}}{ }^{2}$. The normality of residuals' distribution and homogeneity of variances were tested with SAS GLM and UNIVARIATE procedures (SAS ${ }^{\circledast}$ Analytics Pro 12.1 - SAS Institute Inc 2012).

The variance components of random effects of families and family by environment (treatment) interaction $(G \times E)$ were computed from corresponding variances obtained in joint ANOVA (statistical model 1; SAS ${ }^{\oplus}$ Analytics Pro 12.1 - SAS Institute Inc 2012), and expressed in percentage of the total random variation (eqn. 2, eqn. 3):

$$
\begin{gathered}
v c_{f}^{2}=\sigma_{f}^{2} /\left(\sigma_{f}^{2}+\sigma_{f \cdot z}^{2}+\sigma_{e}^{2}\right) \\
v c_{f \cdot z}^{2}=\sigma_{f \cdot z}^{2} l\left(\sigma_{f}^{2}+\sigma_{f \cdot z}^{2}+\sigma_{e}^{2}\right)
\end{gathered}
$$

where $v c_{f}{ }^{2}$ and $v c_{f \cdot z}{ }^{2}$ are the family and family by environment interaction variance components, $\sigma_{\mathrm{f}}{ }^{2}$ is the family variance, $\sigma_{\mathrm{f} \cdot \mathrm{z}}{ }^{2}$ is the variance of family by environment interaction, and $\sigma_{\mathrm{e}}{ }^{2}$ is the variance of random residuals.

The simplified linear model was used for variance analysis of the data from each individual environment (treatment - eqn. 4):

$$
y_{j l m}=\mu+b_{j}+f_{l}+\varepsilon_{j l m}
$$

where $y_{\mathrm{jlm}}$ is an observation of the $m^{\text {th }}$ tree from the $l^{\text {th }}$ family in the $j^{\text {th }}$ block, $\mu$ is the overall mean, $b_{\mathrm{j}}$ is the $j^{\text {th }}$ block effect, $f_{\mathrm{i}}$ is the effect of $l^{\text {th }}$ family, and $\varepsilon_{i j m}$ is the ran- dom residual. The model assumed that random effects are normally distributed with expectation zero and corresponding variances $\sigma_{\mathrm{f}}^{2}$ and $\sigma_{\mathrm{e}}^{2}$. Means of environments (treatments) and families were computed using the SAS MEANS procedure $\left(\mathrm{SAS}^{\oplus}\right.$ Analytics Pro 12.1 - SAS Institute Inc 2012).

\section{Genetic parameters estimate}

Genetic parameters: family variance components $\left(v c_{f}\right)$, coefficients of additive genetic variation $\left(C V_{\mathrm{a}}\right)$, additive heritability coefficients $\left(h_{\mathrm{a}}{ }^{2}\right)$ and their standard errors (se) of each trait were assessed using variances and covariances obtained in the analysis of variances of the SAS MIXED procedure. The variance components of families in each environment (treatment) were derived from corresponding variances and expressed in percentage of the total random variation (eqn. 5):

$$
v c_{f}=\sigma_{f}^{2} /\left(\sigma_{f}^{2}+\sigma_{e}^{2}\right) \cdot 100
$$

The coefficient of additive genetic variation of a trait was calculated for each individual environment (treatment) using the following formula (Falconer 1989, Falconer \& Mackay 1996 - eqn. 6):

$$
C V_{g}=3 \cdot \sigma_{f}^{2} \cdot 100 / \bar{X}
$$

where $\bar{X}$ is the phenotypic mean of the trait. Coefficient 3 was used as progenies in the present experiment were considered as an admixture of half-sibs and full-sibs. The narrow sense individual heritability coefficients were calculated using a formula (eqn. 7):

$$
h_{a}^{2}=3 \cdot \sigma_{f}^{2} /\left(\sigma_{f}^{2}+\sigma_{e}^{2}\right)
$$

where $h_{\mathrm{a}}{ }^{2}$ is the individual additive heritability coefficient. B-type genetic correlations (Burdon 1977) between the same traits assessed on different trees from the same families in different environments (treatments) were estimated using the following formula (eqn. 8):

$$
r_{G x y}=r_{x y} / r_{T P x} r_{T P y}
$$

where $r_{\mathrm{xy}}$ is the product-moment correlation between best linear unbiased predictor (BLUP) values derived from an individual environment (treatment) by variance analysis (SAS MIXED procedure), and $r_{\mathrm{TPX}}$ and $r_{\mathrm{TPy}}$ are the estimated relation between true and predicted family values for a trait at $x$ and $y$ environments (treatments), respectively; $r_{\mathrm{TPX}}$ was calculated as follows (eqn. 9):

$$
r_{T P x}=\frac{h^{2} k}{1+h^{2}(k-1)}
$$

where $h^{2}$ is the individual narrow sense heritability coefficient.

To evaluate the stability of individual families across environments (treatments) and the contribution of each of the family plasticity (in percent) to the family by envi- 


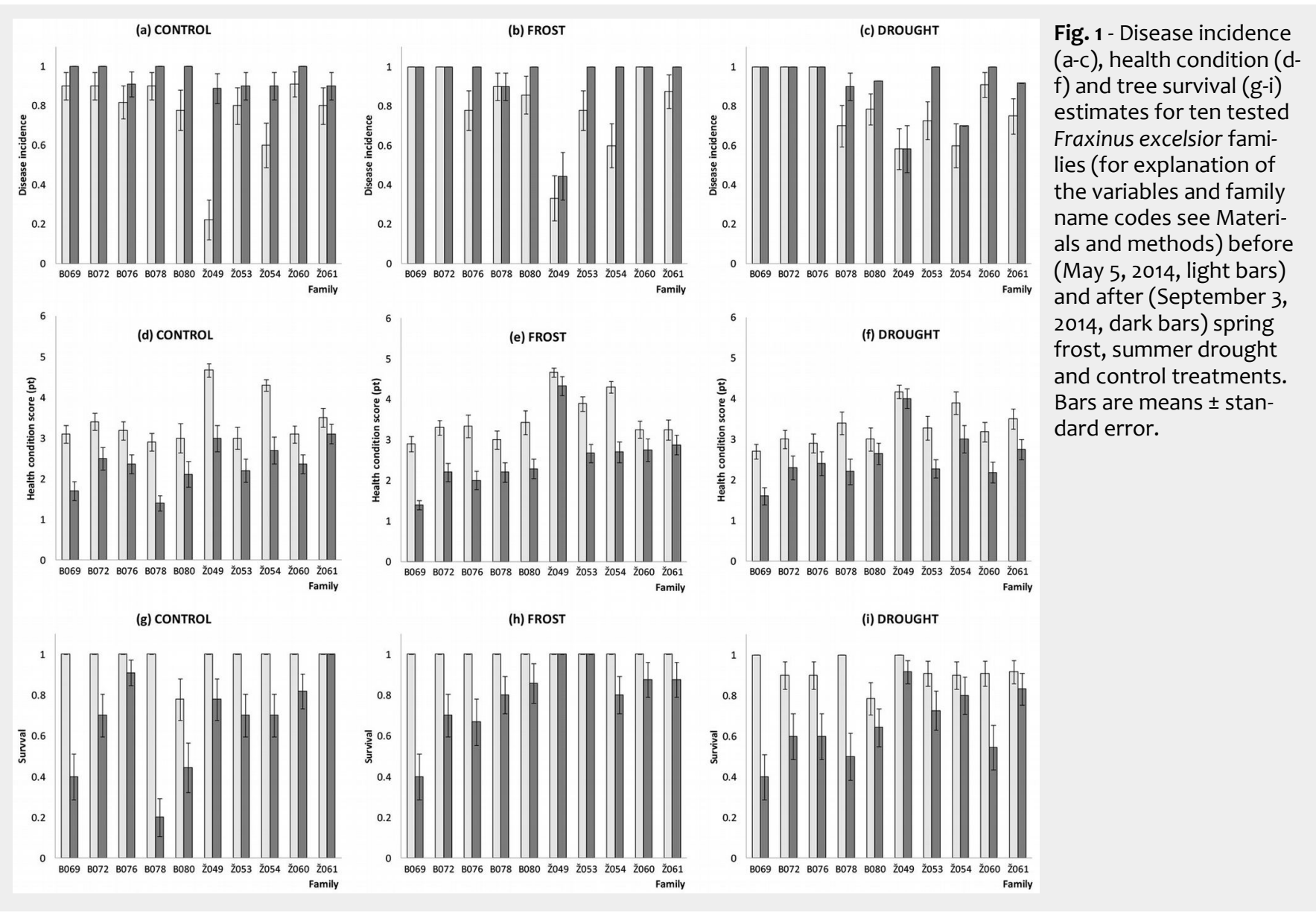

ronment (treatment) interaction $(G \times E)$ variances, the Wricke's ecovalence values (Wricke 1962) were calculated using families' least-squares means obtained within each environment (treatment), using the "Lsmeans" option of the SAS MIXED procedure. The Shukla stability variances were computed and the statistical significance $(P)$ of the ecovalences was tested using the F-test developed by Shukla (1972). In calculating ecovalences, to better fulfill the assumptions behind the linear model thus reducing the scale effects of different environments (treatments) in the joint ANOVA, data were transformed to equal genetic variance using the method of Danell (1988). For each environment (treatment), the assessed values for each tree were multiplied by a scaling factor, which for the $i^{\text {th }}$ environment (treatment) was the mean genetic (family) standard deviations over all environments (treatments) and for the $i^{\text {th }}$ environment (treatment), respectively.

Deviations of families' treatments leastsquares means were calculated by subtracting families' least-squares means obtained in the MIXED analysis at the individual treatments from total least-squares means of treatments. Phenotypic plasticity of each family was estimated as the difference between maximum and minimum least-squares means obtained for different treatments.

Families' least-squares means from MIXED analysis at the individual environments (treatments) were regressed on environment (treatment) least-squares means to estimate the reaction norms of individual families over environments (treatments) according to Finlay \& Wilkinson (1963) using the REG procedure of the SAS software $\left(\mathrm{SAS}^{\oplus}\right.$ Analytics Pro 12.1 - SAS Institute Inc 2012). The following Finlay and Wilkinson parameters were obtained: intercept ( $a$ ) and slope coefficients (b) of linear regression equation, regression residuals and coefficient of determination $\left(R^{2}\right)$.

\section{Results and discussion}

No families were completely resistant and free from disease (Fig. 1 and Fig. 2). This confirms the results of our previous study on resistance of 340 half-sib families from 24 European $F$. excelsior populations, where none of the tested families showed complete resistance to the ash dieback, and only a fraction exhibited reduced susceptibility (Pliura et al. 2011). In clonal studies, differences among $F$. excelsior clones are usually pronounced: a small fraction of the clones exhibit good disease resistance (tolerance), while the majority experience high (and increasing) disease incidence rates becoming heavily damaged over time (McKinney et al. 2011, Kirisits \& Freinschlag 2012, Stener 2013, Pliura et al. 2011).

Mean disease incidence ratio in all three batches of ash seedlings was high (0.770.81 ) already before the treatments (assessed on May 5, 2014), and after the treat- ments (assessed on September 3, 2014) the disease incidence increased up to $0.90-0.95$ (Fig. 1). Such a rapid decline in the number of asymptomatic ash seedlings is not surprising: similar results were obtained also in German trials, where disease incidence increased on average by $16.2 \%$ per year (increasing from $13 \%$ to $94 \%$ in five years Enderle et al. 2013). In the present study, the variation in disease incidence among families was rather small, with one exception: seedlings from family Zo49 were far less frequently infected following spring frost $(0.44 \pm 0.12)$ and summer drought $(0.58 \pm 0.10)$ treatments as compared to other families, where disease incidence ratio following frost and drought treatments was very high and reached respective ratios of 0.90-1.00 and 0.70-1.00 (Tab. 1). ANOVA showed that family effects were statistically significant (Tab. 2). Moreover, for some families (B069, B072 and Z060), symptoms of $H$. fraxineus could be found on all seedlings irrespective of the applied treatment (Fig. 1, Tab. 1). On the other hand, disease symptoms were frequently observed (0.89-1.00) on non-treated (control) seedlings irrespective of their origin (Fig. 1, Tab. 1). Among families from Zeimelis populations, family Z054 had below average disease incidence in the summer drought and control treatments. No statistically significant difference (at $P<0.05$ ) was found in mean disease incidence ratio (all three treatments combined) between 
Fig. 2 - Length of necrotic leader shoot (a-c), total length of necrotic shoots $(d-f)$ and total length of necrotic lesions $(\mathrm{g}-\mathrm{i})$ in ten tested Fraxinus excelsior families (for family name codes see Materials and methods) before (May 5 , 2014, light bars) and after (September 3 2014, dark bars) spring frost, summer drought and control treatments. Bars are means \pm standard error.
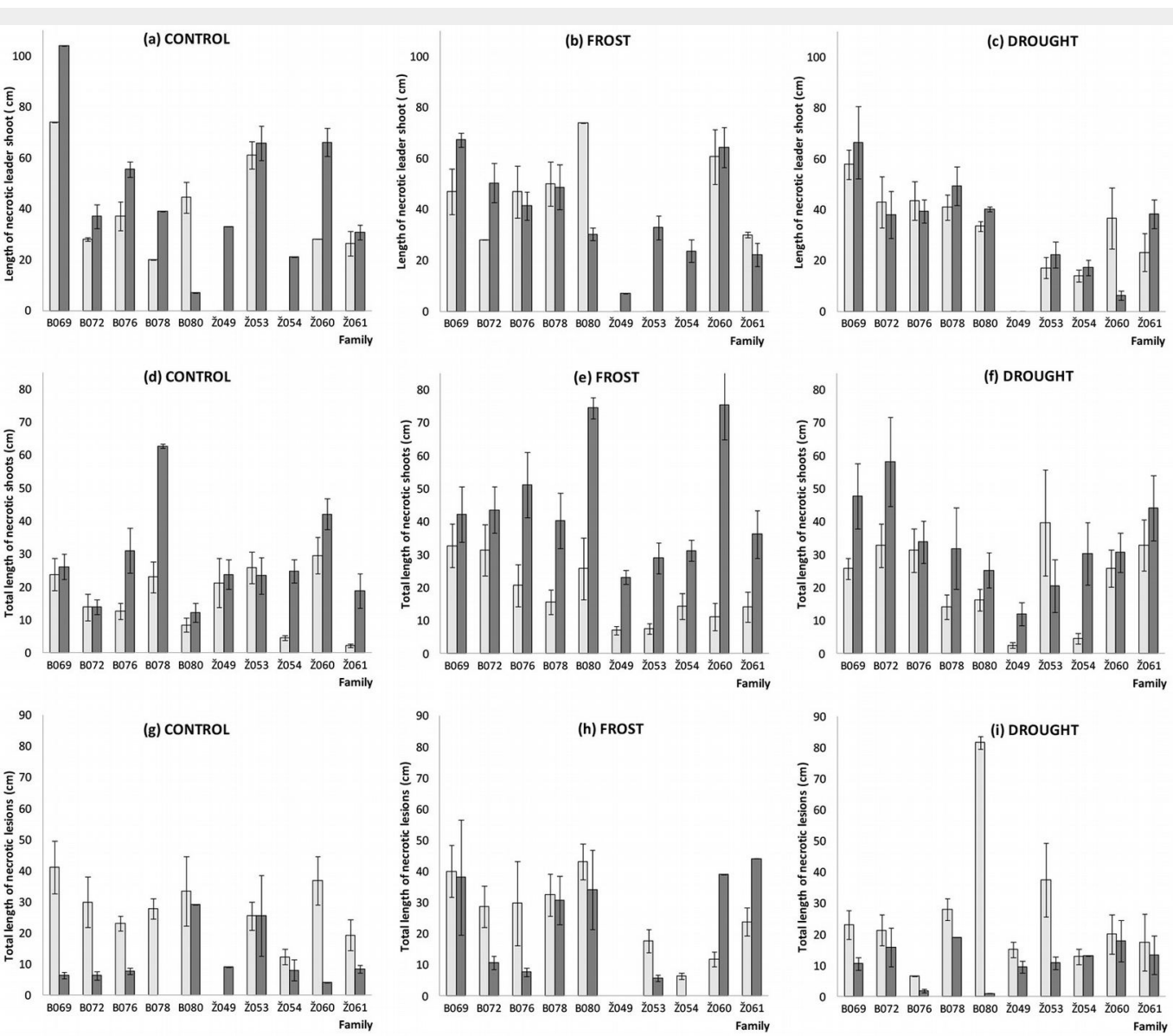

Tab. 1 - Mean values \pm standard error of different trait estimates in ten tested Fraxinus excelsior families from Biržai and Zeimelis populations following spring frost, summer drought and control treatments (estimated on September 3, 2014). For definition of traits see Materials and methods.

\begin{tabular}{|c|c|c|c|c|c|c|c|c|c|}
\hline $\begin{array}{l}\text { Family } \\
\text { code }\end{array}$ & Treatment & $\begin{array}{l}\text { Disease } \\
\text { incidence, } \\
\text { ratio }\end{array}$ & $\begin{array}{c}\text { Health } \\
\text { condition } \\
\text { score, points }\end{array}$ & $\begin{array}{l}\text { Survival } \\
\text { ratio }\end{array}$ & $\begin{array}{l}\text { Length of } \\
\text { necrotic top } \\
\text { shoot, } \mathrm{cm}\end{array}$ & $\begin{array}{c}\text { Length of } \\
\text { necrotic } \\
\text { lateral } \\
\text { shoots, cm }\end{array}$ & $\begin{array}{l}\text { Length of } \\
\text { necrotic } \\
\text { lesions, cm }\end{array}$ & $\begin{array}{c}\text { Bud flushing } \\
\text { phenology, } \\
\text { pt }\end{array}$ & $\begin{array}{c}\text { Tree height, } \\
\text { cm }\end{array}$ \\
\hline \multirow[t]{3}{*}{ B069 } & CONTROL & $00 \pm 0.00$ & $70 \pm 0.23$ & $40 \pm 0.11$ & $104.00 \pm 0.00$ & $26.13 \pm 3.88$ & $6.25 \pm 1.01$ & $1.30 \pm 0.15$ & $111.50 \pm 2.37$ \\
\hline & & & & $0 \pm 0.11$ & & $42.25 \pm 8.44$ & .48 & $1.30 \pm$ & 3.04 \\
\hline & DROUGHT & $1.00 \pm 0.00$ & $1.60 \pm 0.21$ & $0.40 \pm 0.11$ & $66.50 \pm 14.15$ & $47.75 \pm 9.84$ & $10.50 \pm 2.02$ & $2.20 \pm 0.30$ & $101.50 \pm 3.95$ \\
\hline \multirow[t]{3}{*}{ B072 } & CONTROL & $1.00 \pm 0.00$ & $2.50 \pm 0.28$ & $0.70 \pm 0.11$ & $37.00 \pm 4.62$ & $13.92 \pm 2.24$ & $6.25 \pm 1.40$ & $1.60 \pm 0.28$ & $102.00 \pm 3.03$ \\
\hline & FROST & חמת ח + מר & $2.20 \pm 0.23$ & $0.70 \pm 0.11$ & $50.38 \pm 7.67$ & $43.57 \pm 7.06$ & $10.63 \pm 2.13$ & $1.80 \pm 0.25$ & $98.14 \pm 4.53$ \\
\hline & DROUGHT & .00 & 29 & $0.60 \pm 0.11$ & 38.00 & $58.25 \pm 13.56$ & $15.71 \pm 6.21$ & $1.90 \pm 0.24$ & $93.83 \pm 4.47$ \\
\hline \multirow[t]{3}{*}{ B076 } & CONTROL & $0.91 \pm 0.06$ & $2.36 \pm 0.23$ & $0.91 \pm 0.06$ & $55.43 \pm 3.11$ & $30.97 \pm 6.80$ & $7.71 \pm 1.01$ & $2.55 \pm 0.30$ & 2.48 \\
\hline & DROUGHT & $1.00 \pm 0.00$ & $2.40 \pm 0.29$ & $0.60 \pm 0.11$ & $39.33 \pm 4.60$ & $33.83 \pm 6.43$ & $1.83 \pm$ & \pm 0.34 & $97.17 \pm 3.49$ \\
\hline & FROST & \pm 0.00 & $2.00 \pm 0.23$ & $0.67 \pm 0.11$ & & $51.17 \pm 9.81$ & $7.63 \pm 1.32$ & & 6.06 \\
\hline \multirow[t]{3}{*}{ B078 } & CONTROL & & & 0.09 & .00 & $62.75 \pm 0.72$ & 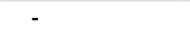 & & 1.73 \\
\hline & FROST & 0.07 & 2.2 & \pm 0.09 & 74 & $40.29 \pm 8.38$ & $30.67 \pm 7.68$ & 2.0 & 4.28 \\
\hline & DROUGHT & $0.90 \pm 0.07$ & $2.20 \pm 0.32$ & $0.50 \pm 0.12$ & $49.33 \pm 7.59$ & $31.83 \pm 12.32$ & $19.00 \pm 0.00$ & $1.80 \pm 0.29$ & $92.20 \pm 4.14$ \\
\hline \multirow[t]{3}{*}{ B080 } & CONTROL & $1.00 \pm 0.00$ & & $0.44 \pm 0.12$ & \pm 0.00 & $12.25 \pm 2.88$ & 29.0 & 38 & 6.36 \\
\hline & DRC & & & $0.64 \pm 0.09$ & $5 \pm 1.01$ & $25.25 \pm 5.38$ & $1.00 \pm 0.00$ & & 4.08 \\
\hline & FROST & $1.00 \pm 0.00$ & $2.29 \pm 0.24$ & $0.86 \pm 0.10$ & $30.25 \pm 2.46$ & $74.50 \pm 3.18$ & $34.00 \pm 12.70$ & $4.29 \pm 0.19$ & $78.50 \pm 4.82$ \\
\hline \multirow[t]{3}{*}{ ZO49 } & CONTROL & $0.89 \pm 0.08$ & $3.00 \pm 0.32$ & $0.78 \pm 0.10$ & $33.00 \pm 0.00$ & $23.75 \pm 4.50$ & $9.00 \pm 0.00$ & $3.78 \pm 0.30$ & $92.43 \pm 2.77$ \\
\hline & & & & & & & - & & 2.67 \\
\hline & DRC & 10 & & $0.92 \pm 0.06$ & - & \pm 3.53 & 9.5 & .32 & 3.70 \\
\hline \multirow[t]{3}{*}{ Z053 } & CONTROL & $0.90 \pm 0.07$ & $2.20 \pm 0.29$ & $0.70 \pm 0.11$ & 65.7 & $23.40 \pm 5.55$ & $25.50 \pm 12.99$ & $2.40 \pm 0.29$ & $88.57 \pm 5.14$ \\
\hline & & & & & & & & & $90.89 \pm 4.69$ \\
\hline & DROUGr & 1.0 & +023 & \pm 0.10 & & \pm 8.08 & 10.7 & \pm 0.39 & \pm 4.80 \\
\hline \multirow[t]{3}{*}{ Z054 } & CONTROL & $0.90 \pm 0.07$ & $2.70 \pm 0.33$ & $0.70 \pm 0.11$ & $21.00 \pm 0.00$ & $24.67 \pm 3.52$ & $8.00 \pm 3.46$ & 0.31 & 4.99 \\
\hline & FROST & $1.00 \pm 0.00$ & $2.70 \pm 0.25$ & $0.80 \pm 0.09$ & $23.67 \pm 4.36$ & $31.19 \pm 3.20$ & - & $2.80 \pm 0.35$ & $93.13 \pm 5.08$ \\
\hline & DROUGHT & $0.70 \pm 0.11$ & $3.00 \pm 0.34$ & $0.80 \pm 0.09$ & $17.25 \pm 3.03$ & $30.30 \pm 9.38$ & 13.0 & $2.80 \pm 0.40$ & $97.13 \pm 4.09$ \\
\hline \multirow[t]{3}{*}{ Z060 } & CONTROL & $1.00 \pm 0.00$ & $2.36 \pm 0.23$ & $0.82 \pm 0.08$ & $66.10 \pm 5.49$ & $42.11 \pm 4.71$ & \pm 0.00 & $3.36 \pm 0.23$ & \pm 5.80 \\
\hline & FROST & & $2.75 \pm 0.28$ & $0.88 \pm 0.09$ & $64.33 \pm 7.81$ & $75.35 \pm 10.37$ & $39.00 \pm 0.00$ & $2.88 \pm 0.35$ & $90.29 \pm 3.78$ \\
\hline & DROUGHT & $1.00 \pm 0.00$ & $2.18 \pm 0.26$ & $0.55 \pm 0.11$ & $6.25 \pm 1.88$ & $30.63 \pm 5.98$ & $17.83 \pm 6.56$ & $2.27 \pm 0.30$ & $98.67 \pm 2.48$ \\
\hline \multirow[t]{3}{*}{ Z061 } & CONTROL & $0.90 \pm 0.07$ & $3.10 \pm 0.24$ & $1.00 \pm 0.00$ & $30.75 \pm 2.77$ & $18.86 \pm 5.22$ & $8.33 \pm 1.17$ & $3.30 \pm 0.33$ & $89.40 \pm 5.04$ \\
\hline & & & 200 & $0.88 \pm 0.09$ & $22.17 \pm 4.49$ & $36.21 \pm 7.20$ & $44.00 \pm 0.00$ & $3.50 \pm 0.18$ & \pm 4.46 \\
\hline & DROUG & $0.92 \pm 0.06$ & $2.75 \pm 0.24$ & $0.83 \pm 0.08$ & $38.25 \pm 5.62$ & $44.11 \pm 9.88$ & $13.25 \pm 6.21$ & $3.58 \pm 0.26$ & $101.00 \pm 4.03$ \\
\hline
\end{tabular}


Tab. 2 - Results from the mixed linear model (2) analysis of different traits in ten tested Fraxinus excelsior families from Biržai and Zeimelis populations (for definition of traits see Materials and methods) following spring frost, summer drought and control treat ments: mean \pm standard error, family variance component as percent of the total random variation $\left(\sigma_{f}^{2}\right) \pm$ standard error, coefficients of phenotypic $\left(C V_{\mathrm{ph}}\right)$ and additive genetic variation $\left(C V_{\mathrm{a}}\right)$, coefficient of additive heritability $\left(h_{\mathrm{a}}^{2}\right) \pm$ standard error. $\left({ }^{*}\right)$ : statistically significant effects at $P<0.05 ;(n s)$ : non-significant effects at $P<0.05$.

\begin{tabular}{|c|c|c|c|c|c|c|c|}
\hline \multirow{2}{*}{ Trait } & \multirow{2}{*}{ Treatment } & \multirow{2}{*}{ Mean \pm se } & \multicolumn{2}{|c|}{ Family variance component } & \multirow{2}{*}{$C V_{\mathrm{ph}}, \%$} & \multirow{2}{*}{$C V_{\mathrm{a}}, \%$} & \multirow{2}{*}{$h_{\mathrm{a}}^{2} \pm \mathrm{se}$} \\
\hline & & & $\sigma_{f}^{2}(\%) \pm \mathrm{se}$ & $P$ & & & \\
\hline \multirow{3}{*}{$\begin{array}{l}\text { Disease incidence ratio before } \\
\text { treatment }\end{array}$} & CONTROL & $0.77 \pm 0.03$ & $19.81 \pm 11.38$ & * & 54.79 & 42.86 & $0.59 \pm 0.28$ \\
\hline & FROST & $0.81 \pm 0.03$ & $24.02 \pm 13.28$ & * & 48.39 & 41.47 & $0.72 \pm 0.31$ \\
\hline & DROUGHT & $0.80 \pm 0.03$ & $11.73 \pm 7.53$ & ns & 50.11 & 29.95 & $0.35 \pm 0.20$ \\
\hline \multirow{3}{*}{$\begin{array}{l}\text { Disease incidence ratio after } \\
\text { treatment }\end{array}$} & CONTROL & $0.95 \pm 0.02$ & $0.89 \pm 2.81$ & ns & 23.00 & 3.76 & $0.03 \pm 0.08$ \\
\hline & FROST & $0.93 \pm 0.02$ & $43.77 \pm 22.10$ & * & 26.80 & 31.38 & $1.00 \pm 0.38$ \\
\hline & DROUGHT & $0.90 \pm 0.02$ & $19.58 \pm 10.94$ & * & 33.41 & 25.82 & $0.59 \pm 0.27$ \\
\hline \multirow{3}{*}{$\begin{array}{l}\text { Health condition score before } \\
\text { treatment, points }\end{array}$} & CONTROL & $3.40 \pm 0.08$ & $21.90 \pm 12.27$ & * & 33.88 & 27.87 & $0.66 \pm 0.29$ \\
\hline & FROST & $3.53 \pm 0.08$ & $26.86 \pm 14.51$ & * & 29.07 & 26.31 & $0.81 \pm 0.33$ \\
\hline & DROUGHT & $3.31 \pm 0.08$ & $9.57 \pm 6.46$ & ns & 37.15 & 20.00 & $0.29 \pm 0.18$ \\
\hline \multirow{3}{*}{$\begin{array}{l}\text { Health condition score after } \\
\text { treatment, points }\end{array}$} & CONTROL & $2.34 \pm 0.09$ & $12.92 \pm 8.20$ & ns & 53.93 & 33.81 & $0.39 \pm 0.22$ \\
\hline & FROST & $2.54 \pm 0.09$ & $35.98 \pm 18.60$ & * & 47.87 & 50.41 & $1.00 \pm 0.37$ \\
\hline & DROUGHT & $2.53 \pm 0.09$ & $17.29 \pm 9.90$ & * & 54.15 & 39.28 & $0.52 \pm 0.25$ \\
\hline \multirow[t]{3}{*}{ Survival ratio before treatment } & CONTROL & $0.98 \pm 0.01$ & - & - & - & - & - \\
\hline & FROST & $1.00 \pm 0.00$ & - & - & - & - & - \\
\hline & DROUGHT & $0.91 \pm 0.02$ & - & - & - & - & - \\
\hline \multirow[t]{3}{*}{ Survival ratio after treatment } & CONTROL & $0.67 \pm 0.03$ & $22.93 \pm 12.63$ & * & 70.36 & 58.98 & $0.69 \pm 0.30$ \\
\hline & FROST & $0.79 \pm 0.03$ & $14.34 \pm 8.90$ & ns & 51.87 & 34.17 & $0.43 \pm 0.24$ \\
\hline & DROUGHT & $0.66 \pm 0.03$ & $7.21 \pm 5.42$ & ns & 71.36 & 33.31 & $0.22 \pm 0.15$ \\
\hline \multirow{3}{*}{$\begin{array}{l}\text { Length of necroticleader shoot } \\
\text { before treatment,cm }\end{array}$} & CONTROL & $42.33 \pm 3.35$ & $62.69 \pm 40.61$ & ns & 47.47 & 68.88 & $1.00 \pm 0.46$ \\
\hline & FROST & $48.31 \pm 4.16$ & & - & 51.65 & - & \\
\hline & DROUGHT & $37.18 \pm 2.93$ & $22.61 \pm 17.01$ & ns & 64.01 & 53.4 & $0.68 \pm 0.41$ \\
\hline \multirow{3}{*}{$\begin{array}{l}\text { Length of necroticleader shoot after } \\
\text { treatment,cm }\end{array}$} & CONTROL & $51.20 \pm 3.14$ & $79.36 \pm 41.59$ & * & 45.08 & 87.76 & $1.00 \pm 0.27$ \\
\hline & FROST & $40.18 \pm 2.51$ & $48.47 \pm 28.41$ & * & 54.50 & 71.59 & $1.00 \pm 0.43$ \\
\hline & DROUGHT & $35.04 \pm 2.89$ & $44.25 \pm 28.67$ & ns & 61.81 & 76.26 & $1.00 \pm 0.47$ \\
\hline \multirow{3}{*}{$\begin{array}{l}\text { Length of necrotic lateral shoots } \\
\text { before treatment, } \mathrm{cm}\end{array}$} & CONTROL & $17.86 \pm 1.61$ & $20.07 \pm 12.93$ & ns & 99.70 & 78.17 & $0.60 \pm 0.31$ \\
\hline & FROST & $20.16 \pm 2.16$ & $9.28 \pm 7.62$ & ns & 117.43 & 62.04 & $0.28 \pm 0.23$ \\
\hline & DROUGHT & $23.88 \pm 2.09$ & $15.88 \pm 11.43$ & ns & 101.05 & 70.94 & $0.48 \pm 0.27$ \\
\hline \multirow{3}{*}{$\begin{array}{l}\text { Length of necrotic lateral shoots } \\
\text { after treatment, } \mathrm{cm}\end{array}$} & CONTROL & $26.89 \pm 1.93$ & $29.31 \pm 19.23$ & ns & 77.14 & 75.69 & $0.88 \pm 0.37$ \\
\hline & FROST & $44.03 \pm 2.57$ & $29.98 \pm 16.93$ & * & 66.10 & 63.92 & $0.90 \pm 0.36$ \\
\hline & DROUGHT & $33.24 \pm 3.00$ & $10.72 \pm 8.59$ & ns & 97.21 & 55.34 & $0.32 \pm 0.24$ \\
\hline \multirow{3}{*}{$\begin{array}{l}\text { Length of necroticlesions before } \\
\text { treatment, } \mathrm{cm}\end{array}$} & CONTROL & $23.05 \pm 1.98$ & $7.39 \pm 8.75$ & ns & 78.74 & 37.23 & $0.22 \pm 0.26$ \\
\hline & FROST & $22.54 \pm 2.74$ & $8.05 \pm 9.32$ & ns & 105.85 & 52.2 & $0.24 \pm 0.28$ \\
\hline & DROUGHT & $18.38 \pm 1.92$ & - & 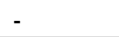 & - & - & - \\
\hline \multirow{3}{*}{$\begin{array}{l}\text { Length of necroticlesions after } \\
\text { treatment, } \mathrm{cm}\end{array}$} & CONTROL & $6.88 \pm 0.61$ & $1.45 \pm 11.94$ & ns & 50.56 & 10.55 & $0.04 \pm 0.63$ \\
\hline & FROST & $7.25 \pm 0.75$ & $41.12 \pm 45.63$ & ns & 46.10 & 55.42 & $1.00 \pm 0.99$ \\
\hline & DROUGHT & $9.00 \pm 1.19$ & $24.49 \pm 24.33$ & ns & 85.43 & 75.33 & $0.73 \pm 0.53$ \\
\hline
\end{tabular}

Biržai and Zeimelis populations. Although the highest disease incidence ratio was generally observed in the control treatment $(0.95 \pm 0.02)$, it did not differ significantly $(P>0.05)$ from frost and drought treatments $(0.93 \pm 0.06$ and $0.90 \pm 0.05$, respectively).

A similar trend was observed also for the damage of individual trees and tree survival ratio within the tested families: rather low health condition scores recorded before the treatments (on May 5, 2014) further declined (mostly due to a large number of seedlings that died) following the treatments (by September 3, 2014 - Fig. 1, Tab. 2). In general, the health condition score of tested trees was low, although it had a tendency to be higher in the spring frost and summer drought treatments than in control $(2.52 \pm 0.09,2.56 \pm 0.09$ and 2.34 \pm 0.09 , respectively - Tab. 2 ). Seedling survival rate was higher following spring frost treatment than in the control or following summer drought treatments $(0.78 \pm 0.03$, $0.67 \pm 0.03$ and $0.66 \pm 0.03$ respectively Tab. 2). Seedling mortality was high (21-31\% during one vegetation season) following all three treatments. Such high mortality rates corresponded well with the results obtained during our previous studies in Lithuanian ash progeny trials, where almost $90 \%$ of the trees died in five years following trial establishment (Pliura \& Baliuckas 2007, Pliura et al. 2011). Results of a F. excelsior clonal trial in Sweden (Stener 2013) indicated lower mortality rates as compared to those found in our previous studies: $33 \%$ mortality recorded during five years at one site (trial established in 1992) and $7 \%$ mortality during two years at another site (trial established in 1995). However, trees in the Swedish trials were older (about 20-yearsold at the time of the last assessment) compared to our study, which could have positively affected tree survival.

Good health condition (score $=4.33$ and 4.00 points) and very high seedling survival rates (1.00 and 0.92$)$ following respective spring frost and summer drought treatments again were found in family Zo49 (Fig. 1, Tab. 1), indicating its good adaptability to environmental stress, higher disease resistance and potential for further breeding. In the control treatment, the best sur- viving family was Z061 $(1.00 \pm 0.00)$ which was among the best also following frost and drought treatments (Fig. 1). In contrast to disease incidence ratio, statistically significant differences $(P<0.001)$ were found between Zeimelis and Biržai populations (all three treatments combined) in mean tree health condition score (2.86 vs. 2.09) and mean survival ratio (0.83 vs. 0.59). This is not surprising since Zeimelis population was among those having the highest complex breeding value index $\left(C B V I_{i}\right)$ and the largest proportion of most healthy trees also in our previous studies (Pliura et al. 2011, 2014). Although there was a high variation in mean health condition scores and ratios of survival among the tested families, neither tree health condition, nor survival differed significantly $(P<0.05)$ among the treatments (Tab. 3 and Tab. 4), indicating a negligible effect of the simulated adverse conditions on health status and survival of the tested ash seedlings.

It must be pointed out that the two most resistant families, Z049 and Z061, had the earliest bud flushing in spring 2014 (mean family scores $=3.54$ and 3.46 , respectively), 
Tab. 3 - Results from joint mixed linear model (1) analysis of variance of traits in ten tested Fraxinus excelsior families from Biržai and Zeimelis populations (for definition of traits see Materials and methods) following frost and control treatments: family and family by treatment interaction variance components and their standard errors for random effects as percent of the total random variation, and F-criteria and probabilities $(P)$ of the fixed effects. $\left(^{*}\right)$ : statistically significant effects at $P<0.05$; (ns): non-significant effects at $P<0.05$.

\begin{tabular}{|c|c|c|c|c|c|c|}
\hline \multirow{3}{*}{ Trait } & \multicolumn{4}{|c|}{ Random effects } & \multirow{2}{*}{\multicolumn{2}{|c|}{$\begin{array}{c}\text { Fixed effects } \\
\text { Treatment }\end{array}$}} \\
\hline & \multicolumn{2}{|c|}{ Families } & \multicolumn{2}{|c|}{ Families $\times$ treatment } & & \\
\hline & $\sigma_{f \cdot t}^{2}(\%) \pm$ se & $\mathbf{P}$ & $\sigma_{f \cdot t}^{2}(\%) \pm$ se & $\mathbf{P}$ & $\mathrm{F}$ & $\mathbf{P}$ \\
\hline Disease incidence before treatment & $23.24 \pm 11.93$ & * & - & - & 1.61 & ns \\
\hline Disease incidence after treatment & $5.59 \pm 9.95$ & ns & $19.64 \pm 11.19$ & * & 0.09 & ns \\
\hline Health condition score before treatment & $23.51 \pm 12.19$ & * & $0.44 \pm 2.15$ & ns & 1.19 & ns \\
\hline Health condition score after treatment & $17.89 \pm 11.02$ & ns & $5.86 \pm 4.68$ & ns & 1.20 & ns \\
\hline Survival ratio before treatment & - & - & - & & - & - \\
\hline Survival ratio after treatment & $7.03 \pm 8.02$ & ns & $12.20 \pm 7.76$ & * & 2.57 & ns \\
\hline Length of necrotic leader shoot before treatment & $16.11 \pm 21.14$ & ns & $9.82 \pm 21.69$ & ns & 1.81 & ns \\
\hline Length of necrotic leader shoot after treatment & $46.34 \pm 28.55$ & ns & $17.39 \pm 12.08$ & * & 1.59 & ns \\
\hline Length of necrotic lateral shoots before treatment & - & - & $13.02 \pm 6.73$ & * & 0.19 & ns \\
\hline Length of necrotic lateral shoots after treatment & $3.85 \pm 11.82$ & ns & $25.48 \pm 15.71$ & * & 7.01 & * \\
\hline Length of necrotic lesions before treatment & $3.01 \pm 7.13$ & ns & $5.03 \pm 7.94$ & ns & 0.04 & ns \\
\hline Length of necrotic lesions after treatment & $20.57 \pm 23.74$ & ns & - & - & 0.21 & ns \\
\hline Tree height after treatment & $5.81 \pm 6.85$ & ns & $6.09 \pm 5.97$ & ns & 3.77 & ns \\
\hline
\end{tabular}

while the latest flushing families B069 and B072 (mean family scores $=1.60$ and 1.77 , respectively) were of comparably low resistance (Fig. 1, Tab. 1). In general, health condition scores and seedling survival ratio showed rather strong positive Pearson's correlation $(R=0.588, P=0.001$ and $R=$ $0.645, P<0.001$, respectively) with the bud flushing phenology scores indicating that early-flushing clones are less susceptible to infections by $\mathrm{H}$. fraxineus. It can be hypothesized that this correlation between health condition and bud flushing phenology might be attributed to the disease development within a tree during the winter period, that is restrained by earlier cambium activity in spring, or to the reallocation of resources between growth and defense. Timing of reallocation of resources between growth and defense with timing of disease infections was hypothesized as an explanation of the correlation between spring phenology and resistance to DED in
Ulmus (Santini et al. 2005, Ghelardini et al. September 2014) was significantly larger ( $P$ 2010). Other studies have also shown that $<0.01$ ) than in the control treatment (Tab. bud flushing and (or) leaf senescence phe- 3). In control, mean length of necrotic nology exhibit a moderate to strong corre- leader shoots of new vegetation season lation with dieback susceptibility (Pliura \& was higher than on previous year's leader Baliuckas 2007, McKinney et al. 2011, Kiri- shoots $(42.33 \pm 3.35$ vs. $51.20 \pm 3.14 \mathrm{~cm}$ ). sits \& Freinschlag 2012, Bakys et al. 2013, However, following spring frost and sumPliura et al. 2011, 2014). Yet these relation- mer drought treatments length of necrotic ships were not consistent in all studies ( $\mathrm{Ki}$ - leader shoots of new vegetation season risits \& Freinschlag 2012). Interestingly, bud was lower (Tab. 2). Following treatments flushing phenology score moderately nega- mean length of necrotic leader shoots tively correlated with mean seedling height tended to be lower than in control environ$(R=-0.376, P=0.041)$.

Significant effects $(P<0.01)$ of the applied treatments were observed for the total length of necrotic lateral shoots, which characterize the spread rate of the disease within a tree and an extent of damage, while this fixed effect was not significant for other studied traits (Tab. 3 and Tab. 4). Following spring frost and summer drought treatments, the total length of necroses in lateral shoots (measured in ment. This mean that treatments reduces the disease damage or the spread of disease within a tree.

The total length of necrotic lesions on ash seedlings has decreased following frost and drought treatments; it has decreased also in non-treated (control) seedlings (Tab. 2). This decrease could be explained by the fact that lesions which have caused shoot dieback were further regarded and measured as necrotic leader or lateral

Tab. 4 - Results from the joint mixed linear model (1) analysis of variance of traits in ten tested Fraxinus excelsior families from Biržai and Zeimelis populations (for the definition of traits and the list of tested families, see Materials and methods) following drought and control treatments: family and family by treatment interaction variance components and their standard errors for random effects as percent of the total random variation, and F-criteria and probabilities $(P)$ of the fixed effects. $(*)$ : statistically significant effects at $P<0.05$; (ns): non-significant effects at $P<0.05$.

\begin{tabular}{|c|c|c|c|c|c|c|}
\hline \multirow{3}{*}{ Trait } & \multicolumn{4}{|c|}{ Random effects } & \multirow{2}{*}{\multicolumn{2}{|c|}{$\begin{array}{c}\text { Fixed effects } \\
\text { Treatment }\end{array}$}} \\
\hline & \multicolumn{2}{|l|}{ Families } & \multicolumn{2}{|c|}{ Families $\times$ treatment } & & \\
\hline & (\%) \pm se & $\mathbf{P}$ & $(\%) \pm \mathrm{se}$ & $\mathbf{P}$ & $\mathbf{F}$ & $\mathbf{P}$ \\
\hline Disease incidence before treatment & $13.17 \pm 7.84$ & * & $2.41 \pm 3.09$ & ns & 0.75 & ns \\
\hline Disease incidence after treatment & $5.81 \pm 6.25$ & ns & $7.55 \pm 5.55$ & ns & 1.35 & ns \\
\hline Health condition score before treatment & $15.02 \pm 8.05$ & * & - & - & 0.95 & ns \\
\hline Health condition score after treatment & $13.74 \pm 8.04$ & * & $1.84 \pm 2.79$ & ns & 1.75 & ns \\
\hline Survival ratio before treatment & - & - & - & - & - & - \\
\hline Survival ratio after treatment & $10.01 \pm 7.16$ & ns & $4.91 \pm 4.23$ & ns & 0.02 & ns \\
\hline Length of necrotic leader shoot before treatment & $3.20 \pm 17.91$ & ns & $29.33 \pm 21.93$ & ns & 0.46 & ns \\
\hline Length of necrotic leader shoot after treatment & $13.54 \pm 25.71$ & ns & $51.49 \pm 29.02$ & * & 1.53 & ns \\
\hline Length of necrotic lateral shoots before treatment & $2.98 \pm 9.03$ & ns & $14.29 \pm 10.74$ & ns & 1.87 & ns \\
\hline Length of necrotic lateral shoots after treatment & - & - & $14.92 \pm 7.89$ & * & 1.21 & ns \\
\hline Length of necrotic lesions before treatment & $0.66 \pm 6.83$ & ns & $4.10 \pm 8.62$ & ns & 1.50 & ns \\
\hline Length of necrotic lesions after treatment & - & - & $21.98 \pm 17.70$ & ns & 1.72 & ns \\
\hline Tree height after treatment & $7.20 \pm 9.07$ & ns & $11.86 \pm 8.32$ & ns & 0.03 & ns \\
\hline
\end{tabular}


shoots, i.e., lesions were merged with the necrotic shoots. When considering the length of necroses in leader and lateral shoots, families Z049, Z054 and Z053 from the Zeimelis population were among the least damaged after spring frost and summer drought treatments (Fig. 2, Tab. 1), while in the control environment, the smallest length of necrotic leader and lateral shoots was observed in families Bo80, B072, Z054 and Z061, which would also suggest that these families are also quite tolerant (Fig. 2).

As two different aspects of resistance have to be estimated, resistance to infection and resistance to disease spread/development within a tree after infection, for the evaluation of genetic resistance to disease of each tested family or clone at juvenile age in tree breeding we would recommend to compute breeding index composed from indexes of disease incidence (to characterize the resistance to infection) and indexes of length of necrotic lesions and length of dry leader and lateral shoots (to characterize the resistance to disease spread within trees after the infection occurs), as well as index of survival rate. This would be a more correct and precise alternative to visual scoring of health condition.

Despite the observed between-population differences in disease resistance traits, joint ANOVA of individual tree data has not revealed a significant population effect for any of the traits studied (data not presented). This is in a good agreement with results reported by Olrik et al. (2007), Stener (2007), McKinney et al. (2011) and Pliura et al. (2014), where weak and nonsignificant population effects on resistance to $H$. fraxineus have been found. The $a b-$ sence of a significant population effect in the present study could be due to a high among-family variation within the tested populations and a low number of tested populations. In contrast, the results of our previous study on resistance of $340 \mathrm{~F}$. excelsior half-sib families from ten Lithuanian and fourteen west European populations showed significant population effects on disease resistance traits (Pliura et al. 2011).

Joint ANOVA revealed significant family effects $(P<0.05)$ for disease incidence and health condition (both assessed before the treatments) in the ash seedling batch assigned for the spring frost treatment (Tab.

Tab. 5 - B-Type genetic correlations between health condition scores and total lengths of necrotic shoots estimated following spring frost, summer drought and control treatments (estimates made in September 3, 2014) of the ten tested Fraxinus excelsior families. For the definition of traits, see Materials and methods.

\begin{tabular}{llcc}
\hline Trait & Treatment & FROST & DROUGHT \\
\hline Health condition & CONTROL & $0.447 \pm 0.118$ & $0.642 \pm 0.096$ \\
score & FROST & - & $0.933 \pm 0.017$ \\
Length of necrotic & CONTROL & $0.096 \pm 0.162$ & $-0.193 \pm 0.183$ \\
lateral shoots & FROST & - & $-0.111 \pm 0.169$ \\
\hline
\end{tabular}

and Lithuania $\left(C V_{a}=30-39 \%\right.$ - Pliura et al. 2011). High $C V_{a}$ values calculated for ash health condition under stressful conditions show good possibilities for resistant families' selection. High heritability coefficients in turn indicate that the most precise detection of resistant tree genotypes by their phenotype can indeed be done under stressful environmental conditions.

For disease incidence trait, family variance components also largely increased following spring frost and summer drought treatments, although $C V_{a}$ values decreased due to the increase of mean disease incidence rate (Tab. 2). Heritability of this trait also increased following both treatments (Tab. 2). Meanwhile, in the control treatment, the family effect for disease incidence became insignificant in autumn 2014 (after the treatments), as all families had equally high infection (Fig. 1, Tab. 1). In general, significant additive genetic control, which is characterized by $C V_{\mathrm{a}}$ and $h_{\mathrm{a}}{ }^{2}$ of resistance traits obtained in this study, corresponded well to the results of recent studies performed in Lithuania, Denmark and Sweden at a family level, where narrow-sense heritabilities ranged between 0.40-0.49 (Pliura et al. 2011) and between $0.37-0.52$ (Kjær et al. 2012), and broadsense heritabilities obtained in clonal studies ranged from moderate to high (Stener 2007, 2013, Olrik et al. 2007, McKinney et al. 2011, Pliura et al. 2014).

Family variance components for the length of necrotic part of leader shoot increased also both following spring frost and summer drought treatments from low and non-significant estimates before treatments to very high estimates after treatments (Tab. 2). Coefficients of additive genetic variation and heritability also became very high (Tab. 2). It can be noticed that family variance components, $C V_{\mathrm{a}}$ and $h_{\mathrm{a}}{ }^{2}$ for this trait increased in the control environment as well. Therefore the increase of genetic parameters for the length of necrotic part of leader shoots cannot be attributed to the impact of stressors (i.e., spring frost or summer drought), but rather to the general development of disease in all the environments studied.

Genetic parameters for the total length of necrotic lateral shoots increased (by September 2014) in the control environment and following spring frost treatment, while they decreased following summer drought treatment (Tab. 2). Family variance components and other genetic parameters for the total length of necrotic lesions increased following treatments (by September 2014), although remained non-significant probably due to the low number of observations for this trait.

B-Type genetic correlations among family means of health condition scores recorded following all treatments (assessed on September 3, 2014) were moderate to high (Tab. 5), indicating that both stress environments had a similar impact on seedling health condition, which was generally bet- 
Tab. 6 - Stability characteristics (for the definition see Materials and methods) of the ten tested Fraxinus excelsior families from Biržai and Zeimelis populations driven from tree health condition scores (assessed on September 3, 2014) following spring frost, summer drought and control treatments.

\begin{tabular}{|c|c|c|c|c|c|c|c|c|c|c|c|c|c|}
\hline \multirow{2}{*}{$\begin{array}{l}\text { Family } \\
\text { code }\end{array}$} & \multirow{2}{*}{ 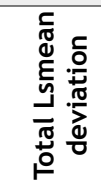 } & \multicolumn{3}{|c|}{$\begin{array}{c}\text { Treatments' Lsmeans } \\
\text { deviations }\end{array}$} & \multirow{2}{*}{ 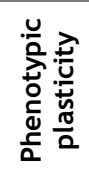 } & \multirow{2}{*}{ 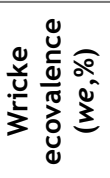 } & \multicolumn{3}{|c|}{ Shukla stability variance } & \multicolumn{4}{|c|}{ Finlay-Wilkinson parameters } \\
\hline & & Control & Frost & Drought & & & Variance & $\mathbf{F}$ & $\mathbf{P}$ & Intercept & $\begin{array}{c}\text { Slope } \\
\text { coefficient }\end{array}$ & Residual & $R^{2}$ \\
\hline B078 & -0.626 & -1.238 & -0.264 & -0.376 & 0.974 & 29.85 & 0.342 & 10.40 & 0.000 & 1.752 & 0.086 & 0.134 & 0.030 \\
\hline Z061 & 0.494 & 1.001 & 0.289 & 0.193 & 0.808 & 20.48 & 0.230 & 7.01 & 0.001 & -1.197 & 1.650 & 0.170 & 0.890 \\
\hline Z049 & 1.280 & 0.869 & 1.484 & 1.486 & 0.617 & 13.30 & 0.145 & 4.41 & 0.012 & 2.762 & 0.430 & 0.084 & 0.530 \\
\hline Z060 & -0.059 & 0.031 & 0.187 & -0.395 & 0.582 & 9.54 & 0.100 & 3.05 & 0.047 & 0.468 & 0.797 & 0.160 & 0.670 \\
\hline B072 & -0.109 & 0.211 & -0.264 & -0.273 & 0.483 & 8.08 & 0.082 & 2.51 & 0.081 & -1.251 & 1.439 & 0.053 & 0.950 \\
\hline B076 & -0.189 & 0.031 & -0.428 & -0.169 & 0.459 & 5.57 & 0.053 & 1.61 & 0.199 & -1.363 & 1.452 & 0.000 & 1.000 \\
\hline Z053 & -0.122 & -0.184 & 0.118 & -0.301 & 0.419 & 4.93 & 0.045 & 1.38 & 0.251 & 0.717 & 0.677 & 0.040 & 0.860 \\
\hline B080 & -0.138 & -0.301 & -0.194 & 0.082 & 0.383 & 4.11 & 0.036 & 1.09 & 0.338 & 0.050 & 0.928 & 0.076 & 0.860 \\
\hline Z054 & 0.357 & 0.474 & 0.146 & 0.451 & 0.328 & 3.54 & 0.029 & 0.88 & 0.416 & -0.515 & 1.335 & 0.009 & 0.990 \\
\hline B069 & -0.920 & -0.843 & -0.920 & -0.997 & 0.154 & 0.63 & -0.006 & -0.18 & - & -1.085 & 1.063 & 0.010 & 0.980 \\
\hline
\end{tabular}

Tab. 7 - Stability characteristics (for the definition see Materials and methods) of the ten tested Fraxinus excelsior families from Biržai and Zeimelis populations driven from total length of necrotic shoots (measured on September 3, 2014) following spring frost, summer drought and control treatments

\begin{tabular}{|c|c|c|c|c|c|c|c|c|c|c|c|c|c|}
\hline \multirow{2}{*}{$\begin{array}{l}\text { Family } \\
\text { code }\end{array}$} & \multirow{2}{*}{ 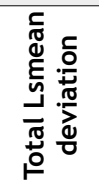 } & \multicolumn{3}{|c|}{$\begin{array}{c}\text { Treatments' Lsmeans } \\
\text { deviations }\end{array}$} & \multirow{2}{*}{ 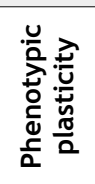 } & \multirow{2}{*}{ 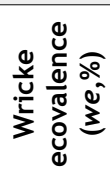 } & \multicolumn{3}{|c|}{ Shukla stability variance } & \multicolumn{4}{|c|}{ Finlay-Wilkinson parameters } \\
\hline & & Control & Frost & Drought & & & Variance & $\mathbf{F}$ & $\mathbf{P}$ & Intercept & $\begin{array}{c}\text { Slope } \\
\text { coefficient }\end{array}$ & Residual & $R^{2}$ \\
\hline B078 & 11.74 & 39.98 & -3.02 & -1.74 & 43.00 & 26.08 & 716.2 & 19.53 & 0.000 & 146.14 & -2.786 & 325.95 & 0.590 \\
\hline B072 & 5.34 & -14.47 & -0.37 & 30.85 & 45.32 & 23.43 & 640.4 & 27.65 & 0.000 & -140.55 & 5.110 & 49.28 & 0.970 \\
\hline B080 & -0.54 & -16.32 & 24.56 & -9.86 & 40.89 & 21.05 & 571.9 & 23.40 & 0.000 & -21.48 & 1.590 & 945.04 & 0.140 \\
\hline Z060 & 12.99 & 16.97 & 25.25 & -3.23 & 28.48 & 9.35 & 236.3 & 10.21 & 0.000 & 77.97 & -0.830 & 225.56 & 0.160 \\
\hline Z061 & -0.62 & -8.96 & -6.30 & 13.41 & 22.37 & 6.51 & 154.8 & 8.09 & 0.000 & -72.61 & 3.028 & 48.69 & 0.920 \\
\hline Z049 & -15.49 & -3.50 & -16.86 & -26.10 & 22.59 & 5.62 & 129.5 & 4.71 & 0.009 & 57.28 & -1.050 & 2.77 & 0.960 \\
\hline B069 & 5.20 & -0.85 & -1.44 & 17.89 & 19.33 & 5.27 & 119.3 & 3.25 & 0.039 & -55.15 & 2.700 & 66.30 & 0.870 \\
\hline Z053 & -10.59 & -3.89 & -12.17 & -15.72 & 11.83 & 1.60 & 14.1 & 0.67 & 0.509 & 27.49 & -0.073 & 3.69 & 0.080 \\
\hline Z054 & -5.49 & -2.48 & -10.36 & -3.63 & 7.88 & 0.78 & -9.3 & -0.40 & - & -1.77 & 0.895 & 35.54 & 0.580 \\
\hline B076 & 3.68 & 4.54 & 5.75 & 0.73 & 5.02 & 0.30 & -23.3 & -1.11 & - & 15.94 & 0.654 & 6.48 & 0.800 \\
\hline
\end{tabular}

ter in frost- and drought-treated seedlings than in the control. B-Type genetic correlations between length of necrotic shoots across treatments were very low and nonsignificant, thus indicating that $\mathrm{G} \times \mathrm{E}$ interaction plays an important role in the variation of disease damage expression (Tab. 5).

Even though the low family by treatment interaction $(G \times E)$ variance component in the variation of health condition score and significant B-type genetic correlations showed that performance of the tested ash families across treatments was rather stable, four out of ten tested families (B078, Z049, Z060 and Z061) had significant $(P<$ $0.05)$ Shukla stability variances, thus significantly contributed to $G \times E$ interaction with Wricke ecovalences (Tab. 6). The highest ecovalence values were obtained for the second most damaged family B078 (29.84\%) and for the second healthiest family Zo61 (20.48\%). The best performing family Z049 showed moderate ecovalence (13.30\%), and the most heavily damaged family B069 showed very low and non-significant ecovalence (0.63\% - Tab. 6). The characteristics of reaction norms and ecovalence estimates of families were not always interrelated, e.g., family B078 with the highest ecovalence and phenotypic plasticity values had the lowest slope coefficient of linear regression, meanwhile family Zo61 having the second highest ecovalence value had the highest slope coefficient (Tab. 6).

Significant $(P<0.05) G \times E$ interaction variance component in the variation of length of necrotic shoots and the absence of significant B-type genetic correlations showed that disease damage in families across environments (treatments) was quite variable. Seven out of ten tested families significantly contributed $(P<0.001)$ to $G \times E$ interaction, with Wricke ecovalences ranging from 5.27 to $26.08 \%$ (Tab. 7). It can be noticed that the slope coefficient of linear regression for the tested families was very different, which indicates different family behavior across treatments.

No generalizations can be made on general plasticity of families, as their performance in terms of different disease damage traits was quite different. In general, high plasticity in disease resistance traits should be considered non-adaptive as it reflects a deterioration in plant health condition and fitness. Eriksson (2001) emphasized that high phenotypic plasticity in adaptive traits may be useful under changing conditions in a short-time period, but it may be detrimental in the long-term, since natural selection is misguided and cannot be fully efficient. In the case of $F$. excelsior, high phenotypic plasticity would aid natural selection in eradicating the least resistant genotypes. This contradicts the conclusion by Ghalambor et al. (2007), who claimed that only plasticity that enhances fitness can facilitate adaptive evolution. In some cases, when environmental conditions are not favorable for disease development, natural selection in such an environment may be misguided, and genotypes of high or average plasticity (e.g., family Z060) would probably survive and show similar resistance (damage levels) as in the most resistant genotypes (e.g., families Z049 and Z054) with low phenotypic plasticity.

\section{Concluding remarks}

None of the tested $F$. excelsior families were completely resistant to $\mathrm{H}$. fraxineus, although the significant among-family variation detected in disease incidence and health condition in each treatment points to the additive mode of gene action, thus to a quantitative resistance to the disease. Such a resistance might be durable in longterm as it combines different plant defense 
mechanisms, thereby diminishing the probability of breaking the resistance due to mutation or adaptation of a pathogen. Neither disease incidence rates, tree health condition scores, nor survival rates differed significantly among the applied treatments (including control), indicating a negligible effect of the simulated adverse conditions on health status of $F$. excelsior. However, the presence of significant genotype by environment (family $\times$ treatment) interactions for disease incidence, total length of necrotic shoots and seedling survival ratios implies that susceptibility of ash families to the dieback disease unequally depends on environmental conditions. This indicates the presence of genetic variation in plasticity and reaction norms across different environments (treatments). Different levels of damage among the ten tested families in two stress-induced events (spring frost and summer drought treatments) and control indicated variable adaptive potential of different families, and warrants testing of material across range of environments in tree breeding for resistance. In general, the plasticity in disease resistance traits should be considered as non-adaptive as it reflects a deterioration of plant health condition and fitness, and adaptive significance of plasticity will depend upon reaction norms and performance of families under certain environmental conditions.

In general, health condition scores and seedling survival ratio showed rather strong positive correlations with the bud flushing phenology scores, in that earlyflushing clones are less susceptible to disease caused by $\mathrm{H}$. fraxineus.

Simulated stress conditions may noticeably contribute to expression of the tree traits which are used to rank tested ash individuals, families or populations for their susceptibility to the dieback. Subsequently, this should enable a better evaluation of the performance of different families, effective family selection, and achievement of a marked genetic gain. High heritability coefficients obtained indicate that stressed environment conditions aid in the detection of resistant tree genotypes by their phenotype for recruiting individuals within families for crossing.

\section{Acknowledgments}

The study was financially supported by the Research Council of Lithuania (project No. MIP-040/2012 - UOSIS 2012-2014). Sincere thanks to nursery staff of the Dubrava Experimental-Educational State Forest Enterprise for assistance in raising seedlings. We are grateful to anonymous reviewers for their comments and constructive advices.

\section{References}

Bakys R, Vasaitis R, Barklund P, Ihrmark K, Stenlid J (2009). Investigations concerning the role of Chalara fraxinea in declining Fraxinus excelsior. Plant Pathology 58: 284-292. - doi: 10.1111/ j.1365-3059.2008.01977.x

Bakys R, Vasaitis R, Skovsgaard JP (2013). Patterns and severity of crown dieback in young even-aged stands of European ash (Fraxinus excelsior L.) in relation to stand density, bud flushing phenotype, and season. Plant Protection Science 49: 120-126. [online] URL: http:// www.agriculturejournals.cz/publicFiles/94542.p df

Bradshaw AD (1965). Evolutionary significance of phenotypic plasticity in plants. Advances in Genetics 13: 115-155. - doi: 10.1016/Soo65-2660 (08)60048-6

Burdon RD (1977). Genetic correlation as a concept for studying genotype-environment interaction in forest tree breeding. Silvae Genetica 26: 5-6. [online] URL: http://sauerlaender-ver lag.com/fileadmin/content/dokument/archiv/sil vaegenetica/26_1977/26-5-6-168.pdf

Danell O (1988). Arbetsgång vid bearbetning av contortaförsök [Planning of work when analyzing trials of Lodgepole pine]. Arbetrapport 219, Institute for Forest Improvement, Uppsala, Sweden, pp. [in Swedish].

Douglas GC, Pliura A, Dufour J, Mertens P, Jacques D, Fernandez-Manjares J, Buiteveld J, Parnuta G, Tudoroiu M, Curnel Y, Thomasset M, Jensen V, Knudsen M, Foffova E, Chandelier A, Steenackers M (2013). Common Ash (Fraxinus excelsior L.). In: “Forest Tree Breeding in Europe: Current State-of-the-Art and Perspectives" (Paques L ed). Series: Managing Forest Ecosystems vol. 25, Springer, Dordrecht, The Netherlands, pp. 403-462. - doi: 10.1007/978-94-0076146-9_9

Enderle R, Peters F, Nakou A, Metzler B (2013). Temporal development of ash dieback symptoms and spatial distribution of collar rots in a provenance trial of Fraxinus excelsior. European Journal of Forest Research 132 (5-6): 865-876. doi: 10.1007/s10342-013-0717-y

Enderle R, Nakou A, Thomas K, Metzler B (2015). Susceptibility of autochthonous German Fraxinus excelsior clones to Hymenoscyphus pseudoalbidus is genetically determined. Annals of Forest Science 72 (2): 183-193. - doi: 10.1007/s13595014-0413-1

Eriksson G (2001). Conservation of noble hardwoods in Europe. Canadian Journal of Forest Research 31: 577-587. - doi: 10.1139/x00-134 Falconer DS (1989). Introduction to quantitative genetics ( $3^{\text {rd }}$ edn). Longman Group Ltd, London, UK, pp. 438.

Falconer DS, Mackay TFC (1996). Introduction to quantitative genetics ( $4^{\text {th }}$ edn). Longman Group Ltd, London, UK, pp. 464.

Finlay KW, Wilkinson GN (1963). The analysis of adaptation in a plant breeding program. Australian Journal of Agricultural Research 14: 742754. - doi: 10.1071/AR9630742

Ghalambor CK, McKay JK, Carrol SP, Reznick DN (2007). Adaptive versus non-adaptive phenotypic plasticity and the potential for contemporary adaptation in new environments. Functional Ecology 21: 394-407. - doi: 10.1111/j.1365-24 35.2007.01283.x

Ghelardini L, Santini A, Black-Samuelsson S, Myking $T$, Falusi $M$ (2010). Bud dormancy release in elm - Ulmus spp. Clones - a case study of photoperiod and temperature responses. Tree Physiology 30: 264-274. - doi: 10.1093/treephys/tpp
110

Gillespie JH, Turelli M (1989). Genotype-environment interactions and the maintenance of polygenic variation. Genetics 121: 129-138. [online] URL: http://www.genetics.org/content/121/1/129 .short

Gregorius HR, Namkoong G (1986). Joint analysis of genotypic and environmental effects. Theoretical and Applied Genetics 72: 413-422. - doi: 10.1007/BFoo288581

Goldstein DB, Holsinger KE (1992). Maintenance of polygenic variation in spatially structured populations: roles for local mating and genetic redundancy. Evolution 46 (2): 421-429. - doi: $10.2307 / 2409861$

Gross A, Holdenrieder O, Pautasso M, Queloz V, Sieber TN (2014). Hymenoscyphus pseudoalbidus, the causal agent of European ash dieback. Molecular Plant Pathology 15 (1): 5-21. - doi: 10.1111/mpp.12073

Gustiene A (2010). Grybo Chalara fraxinea reikšme uosiu džiuties procese [Importance of fungus Chalara fraxinea in the process of ash dieback]. Musu Girios 11: 18-19. [in Lithuanian]

Husson C, Scala B, Caël O, Frey P, Feau N, loos R, Marçais $B$ (2011). Chalara fraxinea is an invasive pathogen in France. European Journal of Plant Pathology 130: 311-324. - doi: 10.1007/s10658-0119755-9

Jain SK (1979). Adaptive strategies: polymorphism, plasticity, and homeostasis. In: "Topics in plant population biology" (Solbrig OT, Jain S, Johnson GB, Raven PH eds). Columbia University Press, New York, USA, pp. 160-187.

Juodvalkis A, Vasiliauskas A (2002). Lietuvos uosynu džiuvimo apimtys ir jas lemiantys veiksniai [The extent and possible causes of dieback of ash stands in Lithuania]. LZUU mokslo darbai, Biomedicinos mokslai 56: 17-22. [in Lithuanian with English summary]

Kirisits T, Freinschlag C (2012). Ash dieback caused by Hymenoscyphus pseudoalbidus in a seed plantation of Fraxinus excelsior in Austria. Journal of Agricultural Extension and Rural Development 4(9): 184-191. [online] URL: http:// www.academicjournals.org/article/article13796 88970_KirisitsandFreinschlag.pdf

Kirisits T, Matlakova M, Mottinger-Kroupa S, Cech TL, Halmschlager E (2009). The current situation of ash dieback caused by Chalara fraxinea in Austria. In: Proceedings of the Conference "IUFRO Working Party 7.02.02" (DogmusLehtijärvi T ed). Egirdir (Turkey) 11-16 May 2009. SDU Faculty of Forestry Journal, Special Issue, pp. 97-119. - [online] URL: http://citeseerx.ist. psu.edu/viewdoc/download?doi=10.1.1.431.6296 \&rep=rep1\&type=pdf\#page $=110$

Kjær ED, McKinney LV, Rostgaard Nielsen L, Nørgaard Hansen L, Hansen JK (2012). Adaptive potential of ash (Fraxinus excelsior) populations against the novel emerging pathogen $\mathrm{Hy}$ menoscyphus pseudoalbidus. Evolutionary Applications 5: 219-228. - doi: 10.1111/j.1752-4571.20 11.00222.x

Kowalski T, Holdenrieder O (2009a). Pathogenicity of Chalara fraxinea. Forest Pathology 39: 1-7. - doi: 10.1111/j.1439-0329.2008.00565.x

Kowalski T, Holdenrieder O (2009b). The teleomorph of Chalara fraxinea, the causal agent of ash dieback. Forest Pathology 39: 304-308. doi: 10.1111/j.1439-0329.2008.00589.x 
Lygis V, Bakys R, Gustiene A, Burokiene D, Matelis A, Vasaitis R (2014). Forest self-regeneration following clear-felling of dieback-affected Fraxinus excelsior: focus on ash. European Journal of Forest Research 133: 501-510. - doi: 10.1007/s10342-014-0780-z

Marshall DR, Jain SK (1968). Phenotypic plasticity of Avena fatua and A. barbata. The American Naturalist 102: 457-467. - doi: 10.1086/282558

McKinney LV, Nielsen LR, Hansen JK, Kjær ED (2011). Presence of natural genetic resistance in Fraxinus excelsior (Oleraceae) to Chalara fraxinea (Ascomycota): an emerging infectious disease. Heredity 106: 788-797. - doi: 10.1038/ hdy.2010.119

Namkoong G, Jonsson A, Eriksson G (1992). Genetic variation in nutrient response functions. Theoretical and Applied Genetics 85: 165-172. doi: 10.1007/BF00222855

Olrik DC, Kjaer ED, Ditlevsen B (2007). Klonforskelle i angreb af asketoptørre [Clonal variation in ash dieback]. Skoven 39: 522-525. [in Danish]

Pliura A, Baliuckas V (2007). Genetic variation in adaptive traits of progenies of Lithuanian and western European populations of Fraxinus excelsior L. Baltic Forestry 13 (1): 28-38. [online] URL: http://www.forestgen.mi.It/content/Pliura $\% 20$ and $\% 20$ Baliuckas\%202007

Pliura A, Lygis V, Suchockas V, Bartkevičius E (2011). Performance of twenty four European Fraxinus excelsior populations in three Lithuanian progeny trials with a special emphasis on resistance to Chalara fraxinea. Baltic Forestry 17: 17-33. [online] URL: http://www.research gate.net/profile/Alfas_Pliura/publication/26259 9916/

Pliura A, Marčiulyniene D, Bakys R, Suchockas V (2014). Dynamics of genetic resistance to Hymenoscyphus pseudoalbidus in juvenile Fraxinus excelsior clones. Baltic Forestry 20 (1): 10-27. [online] URL: http://www.balticforestry.mi.lt/ bf/PDF Articles/2014-20[1]/

Queloz V, Grunig CR, Berndt R, Kowalski T, Sieber TN, Holdenrieder O (2010). Cryptic speciation in Hymenoscyphus albidus. Forest Pathology 41: 133-142. - doi: 10.1111/j.1439-0329.2010. 00645.x

Santini A, Fagnani A, Ferrini F, Ghelardini L, Mittempergher $L$ (2005). Variation among Italian and French elm clones in their response to Ophiostoma novo-ulmi inoculation. Forest Pathology 35: 183-193. - doi: 10.1111/j.1439-0329.20 05.00401.x

SAS Institute Inc (2012). SAS ${ }^{\circledR}$ Analytics Pro 12.1. SAS Institute Inc, Cary, NC, USA. [online] URL: http://support.sas.com/documentation/121/

Scheiner SM (1993a). Genetics and evolution of phenotypic plasticity. Annual Review of Ecological Systems 24: 35-68. - doi: 10.1146/annurev. es.24.110193.000343

Scheiner SM (1993b). Plasticity as a selectable trait: reply to Via. The American Naturalist 142 (2): 371-373. - doi: 10.1086/285544

Schlichting CD, Levin DA (1984). Phenotypic plasticity of annual phlox: tests of some hypotheses. American Journal of Botany 71 (2): 252-260. - doi: $10.2307 / 2443753$

Schlichting CD (1986). The evolution of phenotypic plasticity in plants. Annual Review of Ecological Systems 17: 667-693. - doi: 10.1146/annu rev.es.17.110186.003315

Schmalhausen II (1949). Factors of evolution. Chicago University Press, Chicago, IL, USA, pp. 327. [online] URL: http://psycnet.apa.org/psyc info/1950-02268-000

Shukla GK (1972). Some statistical aspects of partitioning genotype-environment components of variability. Heredity 29: 237-45. - doi: 10.1038/ hdy.1972.87
Skovsgaard JP, Thomsen IM, Skovgaard IM, Martinussen T (2010). Associations among symptoms of dieback in even-aged stands of ash (Fraxinus excelsior L.). Forest Pathology 40: 718. - doi: 10.1111/j.1439-0329.2009.00599.x

Stener L-G (2007). Studie av klonskillnader i känslighet för askskottsjuka [A study on clonal variation in susceptibility to ash dieback]. Arbetsrapport från Skogforsk 648, Uppsala, Sweden, pp. 14. [in Swedish]

Stener L-G (2013). Clonal differences in susceptibility to the dieback of Fraxinus excelsior L. in southern Sweden. Scandinavian Journal of Forest Research 28 (3): 205-216. [online] URL: http://www.tandfonline.com/doi/abs/10.1080/0 2827581.2012.735699\#.VcNiQfntnPI

Sultan SE (1987). Evolutionary implications of phenotypic plasticity in plants. Evolutionary Biology 21: 127-178. - doi: 10.1007/978-1-4615-69 86-2_7

Sultan SE (1995). Phenotypic plasticity and plant adaptation. Acta Botanica Neerlandica 44 (4): 363-383. - doi: 10.1111/j.1438-8677.1995.tboo79 $3 . x$

Sultan SE, Bazzaz FA (1993). Phenotypic plasticity in Polygonum persicaria. I. Diversity and uniformity in genotypic norms of reaction to light. Evolution 47 (4): 1009-1031. - doi: 10.2307/ 2409972

Taylor DR, Aarssen LW (1988). An interpretation of phenotypic plasticity in Agropyron repens (Graminae). American Journal of Botany 75 (3): 401-413. - doi: 10.2307/2443987

Wricke G (1962). Über eine Methode zur Erfassung der ökologischen Streubreite in Feldversuchen [About a method for detection of environmental variation range in field trials]. $\mathrm{Z}$. Pflanzenzucht 47: 92-96. [in German] 